\title{
Method Development and Validation for Simultaneous Estimation of Montelukast Sodium and Desloratadine by RP-HPLC
}

\author{
Bonthu Mohan Gandhi' ${ }^{1}$ Atmakuri Lakshmana Rao ${ }^{2 *}$, Jangala Venkateswara Rao ${ }^{3}$ \\ ${ }^{1}$ Sri Vasavi Institute of Pharmaceutical Sciences, Tadepalligudem, India \\ ${ }^{2} \mathrm{~V}$. V. Institute of Pharmaceutical Sciences, Gudlavalleru, India \\ ${ }^{3}$ Bharat Institute of Pharmacy, Mangalpally, India \\ Email: ${ }^{\text {dralrao@gmail.com }}$
}

Received 8 June 2015; accepted 10 July 2015; published 13 July 2015

Copyright (C) 2015 by authors and Scientific Research Publishing Inc.

This work is licensed under the Creative Commons Attribution International License (CC BY). http://creativecommons.org/licenses/by/4.0/

(c) (i) Open Access

\begin{abstract}
A novel, precise, accurate, rapid and cost effective isocratic reverse-phase high performance liquid chromatographic (RP-HPLC) method was developed, optimized and validated for the simultaneous estimation of Montelukast Sodium (MON) and Desloratadine (DES) in pharmaceutical dosage forms. The drugs were estimated using Hypersil BDS C18 $(250 \mathrm{~mm} \times 4.6 \mathrm{~mm}$ I.D., $5 \mu$ particle size) column. The mobile phase composed of orthophosphoric acid and water in the ratio of 20:80 v/v, at a flow rate of $1.0 \mathrm{ml} / \mathrm{min}$ was used for the separation. Detection was carried out at $280 \mathrm{~nm}$. The linearity range obtained was $10-30 \mu \mathrm{g} / \mathrm{ml}$ for MON and $5-15 \mu \mathrm{g} / \mathrm{ml}$ for DES with retention times of $2.929 \mathrm{~min}$ and $4.439 \mathrm{~min}$ for MON and DES respectively. The correlation coefficient values were found to be 0.999 . Precision studies showed \% RSD values less than $2 \%$ for both the drugs in all the selected concentrations. The percentage recoveries of MON and DES were in the range of 99.59\% - 99.82\% and $99.60 \%-99.80 \%$ respectively. The limit of detection (LOD) and limit of quantification (LOQ) were $0.176 \mu \mathrm{g} / \mathrm{ml}, 0.587 \mu \mathrm{g} / \mathrm{ml}$ for MON and $0.087 \mu \mathrm{g} / \mathrm{ml}, 0.292 \mu \mathrm{g} / \mathrm{ml}$ for DES respectively. The method was validated as per the International Conference on Harmonization (ICH) guidelines. The proposed validated method was successfully used for the quantitative analysis of commercially available tablet dosage forms.
\end{abstract}

\section{Keywords}

Montelukast Sodium, Desloratadine, HPLC, Validation

\footnotetext{
${ }^{*}$ Corresponding author.
}

How to cite this paper: Gandhi, B.M., Rao, A.L. and Rao, J.V. (2015) Method Development and Validation for Simultaneous Estimation of Montelukast Sodium and Desloratadine by RP-HPLC. American Journal of Analytical Chemistry, 6, $651-658$. 


\section{Introduction}

Montelukast Sodium (MON) (Figure 1) is chemically 2-[1-(\{[(1R)-1-\{3-[(E)-2-(7-chloroquinolin-2-yl)ethenyl] phenyl\}-3-[2-(2-hydroxypropan-2-yl)phenyl]propyl]sulfanyl\} methyl)cyclopropyl]acetic acid [1]. MON is a leukotriene receptor antagonist (LTRA) used for the maintenance treatment of asthma and to relieve symptoms of seasonal allergies [2] [3]. MON selectively antagonizes leukotriene $\mathrm{D}_{4}\left(\mathrm{LTD}_{4}\right)$ at the cysteinyl leukotriene receptor, $\mathrm{CysLT}_{1}$, in the human airway. MON inhibits the actions of $\mathrm{LTD}_{4}$ at the $\mathrm{CysLT}_{1}$ receptor, preventing airway edema, smooth muscle contraction and enhanced secretion of thick, viscous mucus [4]-[7].

Desloratadine (DES) (Figure 2) is chemically 8-chloro-6, 11-dihydro-11-(4-deserdinylidene)-5H-benzo [5] [6] cyclohepta[1, 2-b]pyridine [3]. DES is a second generation, tricyclic antihistamine that which has a selective and peripheral $\mathrm{H}_{1}$-antagonist action [4]. It is the active descarboethoxy metabolite of Loratidine. DES has a long-lasting effect and does not cause drowsiness because it does not readily enter the central nervous system [5]-[7].

MON with DES is used for the treatment of persistent allergic rhinitis [8]. Literature survey reveals that few analytical methods are available for the simultaneous estimation of MON and DES in pharmaceutical formulations by using UV [9]-[11] and HPLC [12]-[15]. Hence, we made an attempt to develop a simple method for the simultaneous estimation of MON and DES by RP-HPLC in pharmaceutical dosage forms. The proposed method was optimized and validated as per the International Conference on Harmonization (ICH) guidelines [16].

\section{Experimental}

\subsection{Instrumentation}

The analysis of the drug was carried out on a Waters HPLC system equipped with 2487 pump and UV/Visible dual absorbance detector was used. Hypersil BDS C18 column ( $250 \mathrm{~mm} \times 4.6 \mathrm{~mm}$ I.D., $5 \mu$ particle size) was used. The output of signal was monitored and integrated using Waters Empower 2 software.

\subsection{Chemicals and Solvents}

The working standards of Montelukast Sodium and Desloratadine were provided as gift samples by Spectrum Pharma Research Solutions, Hyderabad, India. Methanol (HPLC grade); Milli-Q water and orthophosphoric acid (AR grade) were obtained from Qualigens Ltd, Mumbai, India.

\subsection{Mobile Phase Preparation}

Mobile phase was prepared by mixing $20 \mathrm{ml}$ orthophosphoric acid and $80 \mathrm{ml}$ of Milli-Q water. Above mixture

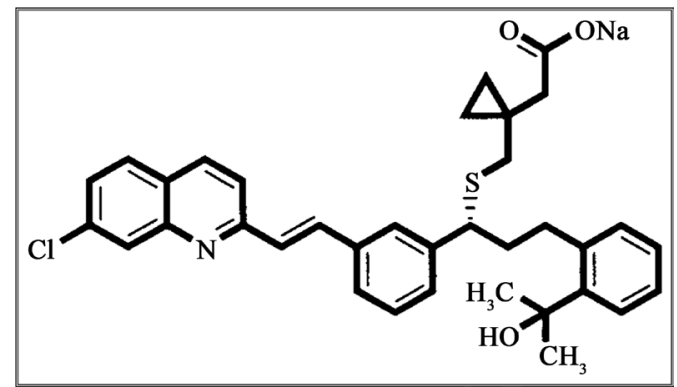

Figure 1. Chemical structure of MON.

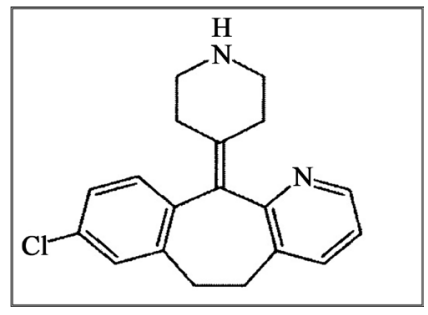

Figure 2. Chemical structure of DES. 
was degassed in an ultrasonic water bath for 5 minutes and filtered through $0.45 \mu$ filter under vacuum.

\subsection{Diluent Preparation}

Methanol was used as diluent.

\subsection{Standard Solution Preparation for MON and DES}

The standard solutions were prepared by weighing accurately $10 \mathrm{mg}$ of MON and $5 \mathrm{mg}$ of DES [working standards] and transferred into two $100 \mathrm{ml}$ clean dry volumetric flasks. About $70 \mathrm{ml}$ of diluent was added to each flask and sonicated to dissolve the powders completely. Final volumes were adjusted to the mark with diluent. From the stock solutions $5 \mathrm{ml}$ was transferred into $25 \mathrm{ml}$ volumetric flask and diluted up to the mark with same diluent to produce the concentrations of $20 \mu \mathrm{g} / \mathrm{ml}$ of MON and $10 \mu \mathrm{g} / \mathrm{ml}$ of DES.

\subsection{Sample Solution Preparation for MON and DES}

Twenty tablets of MON and DES were weighed and then finely powdered. An accurately weighed portion of the powder equivalent to $10 \mathrm{mg}$ of MON and $5 \mathrm{mg}$ of DES was transferred into $100 \mathrm{ml}$ volumetric flask. About 70 $\mathrm{ml}$ of diluent was added and sonicated to dissolve the powder completely. From the above filtrate pip petted out $5 \mathrm{ml}$ into a $25 \mathrm{ml}$ volumetric flask and diluted with the diluent. Final volume was adjusted to the mark with diluent. From the stock solution $5 \mathrm{ml}$ was transferred into $25 \mathrm{ml}$ volumetric flask and diluted up to the mark with same diluent to produce the concentrations of $20 \mu \mathrm{g} / \mathrm{ml}$ of MON and $10 \mu \mathrm{g} / \mathrm{ml}$ of DES.

\subsection{Chromatographic Conditions}

A Hypersil BDS C18 $(250 \mathrm{~mm} \times 4.6 \mathrm{~mm}$ I.D., $5 \mu \mathrm{m}$ particle size $)$ column was used for analysis at ambient temperature. The mobile phase orthophosphoric acid and Milli-Q water (20:80 v/v) was pumped through the column at a flow rate of $1.0 \mathrm{ml} / \mathrm{min}$. The sample injection volume was $10 \mu \mathrm{l}$. Detection was carried out at 280 $\mathrm{nm}$ and chromatographic run time was 6 min.

\section{Method Development \& Method Validation}

\subsection{Method Development}

To develop a suitable and robust HPLC method for the simultaneous estimation of MON and DES, different mobile phases were employed to achieve the best separation and resolution. The method development was made with Hypersil BDS C18 column ( $250 \mathrm{~mm} \times 4.6 \mathrm{~mm}$ I.D., $5 \mu$ particle size $)$ with the mobile phase composed of orthophosphoric acid and water in the ratio of $20: 80 \mathrm{v} / \mathrm{v}$, at a flow rate of $1.0 \mathrm{ml} / \mathrm{min}$ was used for the separation.

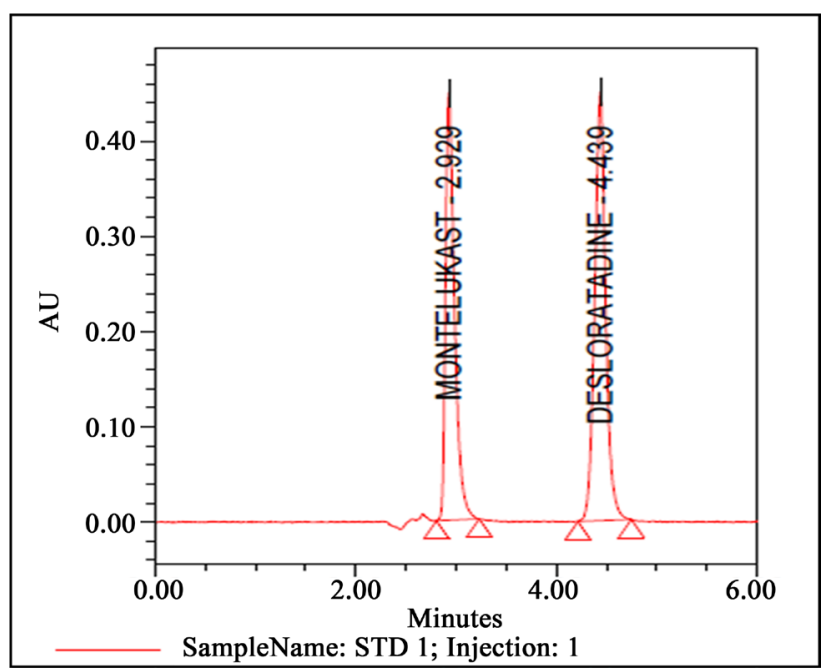

Figure 3. A typical HPLC chromatogram showing peaks of MON and DES. 
Detection was carried out at $280 \mathrm{~nm}$. The typical chromatogram of MON and DES was shown in Figure 3.

\subsection{Method Validation}

According to ICH guidelines, the developed method was validated to assure the reliability of the results of the analysis for different parameters like specificity, system suitability, precision, accuracy, linearity, LOD, LOQ, robustness and ruggedness.

\subsubsection{Specificity}

Specificity is the ability of a method to discriminate between the analytes of interest and other components that are present in the sample. Studies are designed to evaluate the degree of interference, if any, which can be attributed to other analyte, impurities, degradation products, reagent blanks and excipients. A study to establish the interference of blank and placebo were conducted. Diluent and placebo were injected into the chromatograph in the above chromatographic conditions and the blank and placebo chromatograms were recorded. Chromatograms of blank and placebo showed no peaks at the retention times of MON and DES peaks. This indicates that the diluent and placebo used in the sample preparation did not interfere in simultaneous estimation of MON and DES.

\subsubsection{System Suitability}

The system suitability parameters were determined by injecting the standard solutions of MON and DES. Parameters such as number of theoretical plates, tailing factor, retention time and resolution were determined. System suitability parameter values were shown in Table 1.

\subsubsection{Precision}

The precision of an analytical procedure expresses the closeness of measurements obtained from multiple sampling of the same homogenous sample under the prescribed conditions. Precision may be considered at three levels: repeatability, intermediate precision and reproducibility. The precision of an analytical procedure is usually expressed as the variance, standard deviation or coefficient of variation of a series of measurements. Precision of the method was performed as system precision and method precision.

To study the system precision, five replicate mixed standard solutions of MON and DES were injected. The percent relative standard deviation (\% RSD) was calculated. The \% RSD of peak areas of MON and DES should not be more than 2.0. Results of system precision studies are shown in Table 2.

To study the method precision, five replicate mixed sample solutions of MON and DES were injected. The percent relative standard deviation (\% RSD) was calculated. The \% RSD of peak areas of MON and DES should not be more than 2.0. Results of method precision studies were shown in Table 3.

\subsubsection{Accuracy}

The accuracy of an analytical procedure expresses the closeness of agreement between the value which is accepted either as a conventional true value or an accepted reference value and value found. The accuracy of the method was determined by standard addition method. A known amount of standard drug was added to the fixed amount of pre-analyzed tablet solution. Percent recovery was calculated by comparing the area before and after the addition of the standard drug. The standard addition method was performed at three concentration levels of $50 \%, 100 \%$ and $150 \%$. The solutions were analyzed in triplicate at each level as per the proposed method. The percent recovery and \% RSD of peak areas for MON and DES at each level was calculated. The \% Recovery for each level should be between $98.0 \%$ and $102.0 \%$. Recovery studies for MON and DES results were shown in Table 4.

\subsubsection{Linearity}

The linearity of the analytical procedure is its ability (within a given range) to obtain the test results which are directly proportional to the concentration of analyte in the sample. Linearity was performed by preparing mixed standard solutions of MON and DES at different concentration levels including working concentration mentioned in experimental condition i.e., $10-30 \mu \mathrm{g} / \mathrm{ml}$ for MON and 5 - $15 \mu \mathrm{g} / \mathrm{ml}$ for DES respectively. Ten micro litres of each concentration was injected in duplicate into the HPLC system. The response was read at $280 \mathrm{~nm}$ and the corresponding chromatograms were recorded. From these chromatograms, the mean peak areas were 
calculated and linearity plots of concentration over the mean peak areas were constructed individually. The regressions of the plots were computed by least square regression method. The correlation coefficient should be not less than 0.99. Linearity plots are shown in Figure 4 \& Figure 5. Linearity results were shown in Table 5 \& Table 6.

Table 1. System suitability parameters for MON and DES.

\begin{tabular}{ccccc}
\hline Drug & Theoretical plates & Tailing factor & Retention time & Resolution \\
MON & 5345 & 1.164 & 2.929 min. & - \\
DES & 8501 & 1.056 & 4.439 min. & 8.246 \\
\hline
\end{tabular}

Table 2. System precision for MON and DES.

\begin{tabular}{ccc}
\hline S. No. & MON Peak Area & DES Peak Area \\
\hline 1 & $2,810,887$ & $3,426,286$ \\
2 & $2,812,494$ & $3,424,376$ \\
3 & $2,810,808$ & $3,420,684$ \\
4 & $2,815,063$ & $3,422,650$ \\
5 & $2,811,717$ & $3,421,187$ \\
Mean & $2,812,194$ & $3,423,037$ \\
SD & 1744.845 & 2316.12 \\
\% RSD & 0.06 & 0.06 \\
\hline
\end{tabular}

Table 3. Method precision for MON and DES.

\begin{tabular}{ccc}
\hline S. No. & MON Peak Area & DES Peak Area \\
\hline 1 & $2,812,954$ & $3,420,257$ \\
2 & $2,813,565$ & $3,422,883$ \\
3 & $2,817,759$ & $3,428,553$ \\
4 & $2,813,565$ & $3,422,883$ \\
5 & $2,812,954$ & $3,423,898$ \\
Mean & $2,814,159$ & $3,423,695$ \\
SD & 2035.29 & 3032.32 \\
\% RSD & 0.07 & 0.08 \\
\hline
\end{tabular}

Table 4. Recovery studies for MON and DES.

\begin{tabular}{ccc}
\hline \% Level & \% Mean recovery of MON & \% Mean recovery of DES \\
\hline 50 & 99.82 & 99.80 \\
100 & 99.59 & 99.60 \\
150 & 99.71 & 99.73 \\
\hline
\end{tabular}

Table 5. Linearity of MON.

\begin{tabular}{ccr}
\hline S. No. & Concentration $(\mu \mathrm{g} / \mathrm{ml})$ & Mean peak area \\
\hline 1 & 10 & $1,400,967$ \\
2 & 15 & $2,115,685$ \\
3 & 20 & $2,819,203$ \\
4 & 25 & $3,528,621$ \\
5 & 30 & $4,224,806$ \\
\hline
\end{tabular}


Table 6. Linearity of DES.

\begin{tabular}{ccc}
\hline S. No. & Concentration $(\mu \mathrm{g} / \mathrm{ml})$ & Mean peak area \\
\hline 1 & 5 & $1,719,571$ \\
2 & 7.5 & $2,574,693$ \\
3 & 10 & $3,428,501$ \\
4 & 12.5 & $4,280,413$ \\
5 & 15 & $5,148,147$ \\
\hline
\end{tabular}

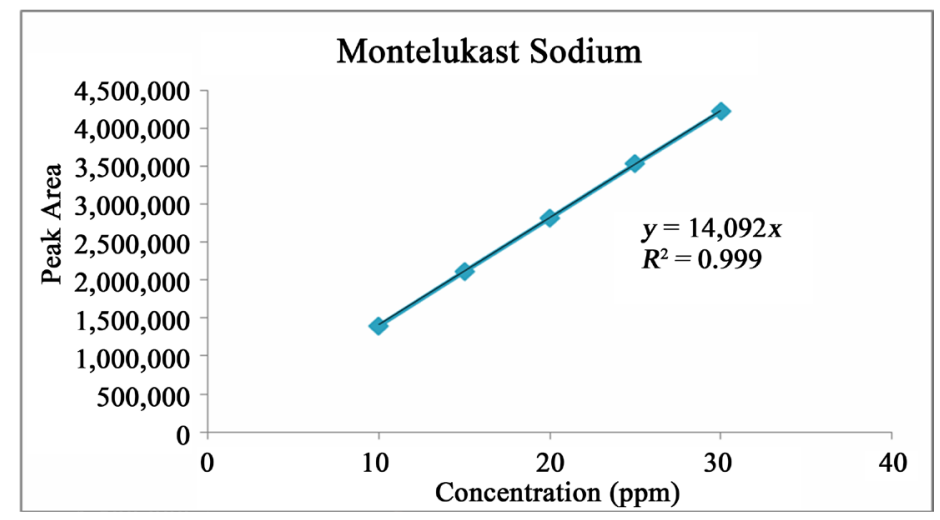

Figure 4. Linearity curve for MON.

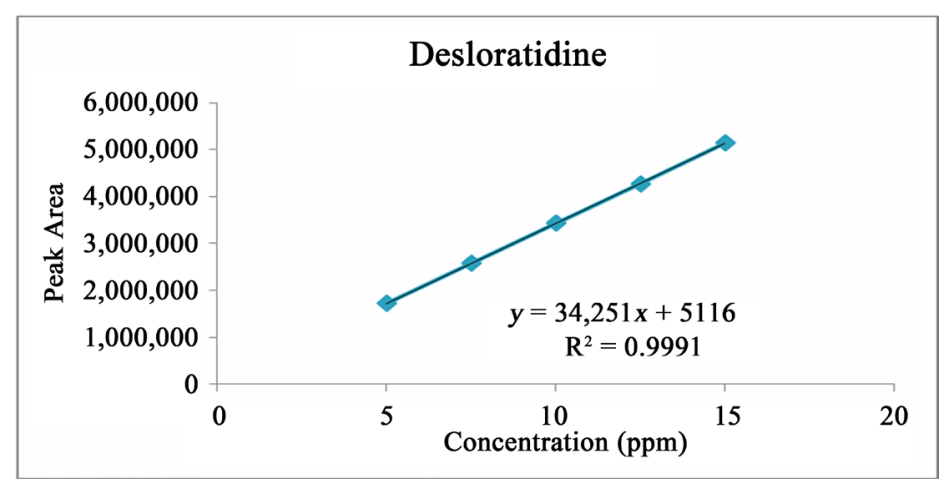

Figure 5. Linearity curve for DES.

\subsubsection{Limit of Detection and Limit of Quantification}

Limit of detection (LOD) is defined as the smallest concentration that can be detected but not necessarily quantified as an exact value.

LOD is calculated from the formula; $\mathrm{LOD}=3.3 \sigma / \mathrm{S}$

where, $\sigma=$ standard deviation of the response, $S=$ slope of calibration curve.

Limit of quantification (LOQ) is defined as the lowest concentration that can be quantified reliably with a specified level of accuracy and precision.

LOQ is calculated from formula; $\mathrm{LOQ}=10 \sigma / S$

where, $\sigma=$ standard deviation of the response, $S=$ slope of calibration curve.

For this study six replicates of the analyte at lowest concentration were measured and quantified. The LOD and LOQ values of MON and DES were given in Table 7.

\subsubsection{Robustness}

The robustness of an analytical procedure is a measure of its capacity to remain unaffected by small, but deliberate variations in method parameter and provides an indication of its reliability during normal usage. As part of the robustness, deliberate change in the flow rate, mobile phase composition, temperature variation was made to 
evaluate the impact on the method. The typical variations are variation in flow rate by $\pm 0.2 \mathrm{ml} / \mathrm{min}$ and variation in temperature varied from $\pm 10 \%$. Mixed samples of both MON and DES were analyzed under these changed experimental conditions. The results of robustness study are shown in Table 8.

\subsubsection{Ruggedness}

The ruggedness of an analytical method is determined by analysis of aliquots from homogenous lots by different analysts using operational and environmental conditions that may differ but are still within the specified parameters of the assay. The assay was performed in different condition, different analyst and different dates. The results of ruggedness study are given in Table 9 .

\section{Results and Discussion}

The HPLC procedure was optimized with a view to develop a simultaneous estimation method in tablet dosage form using Hypersil BDS C18 column $(250 \mathrm{~mm} \times 4.6 \mathrm{~mm}$ I.D., $5 \mu$ particle size) in isocratic mode with mobile phase composed of orthophosphoric acid and water in the ratio of 20:80 v/v resulted in peak with good shape and resolution. The flow rate was $1.0 \mathrm{ml} / \mathrm{min}$ and both the components were measured with UV detector at 280 nm.

Typical chromatograms of the drugs MON and DES shown that no interfering peaks were found in the chromatogram of the formulation within the run time indicating that excipients used in tablet formulations did not interfere with the estimation of the drugs by the proposed HPLC method. The retention times for MON and DES was found to be 2.929 min and 4.439 min respectively and the peak shape was good. The number of theoretical plates calculated was 5345 for MON and 8501 for DES and tailing factor was 1.164 for MON and 1.056 for DES, which indicates efficient performance of the column. The results of system suitability parameters indicate good performance and hence the method is specific.

For system precision study, the \% RSD was found to be 0.06 and 0.06 for MON and DES respectively, which are well within the acceptable criteria of not more than 2.0. For method precision study, the \% RSD was found to be 0.07 and 0.08 for MON and DES respectively, which are well within the acceptable criteria of not more than 2.0. This reveals that the method is quite precise.

Table 7. LOD and LOQ for MON and DES.

\begin{tabular}{cccc}
\hline S. No. & Parameter & MON & DES \\
\hline 1 & LOD $(\mu \mathrm{g} / \mathrm{ml})$ & 0.176 & 0.087 \\
2 & LOQ $(\mu \mathrm{g} / \mathrm{ml})$ & 0.587 & 0.292 \\
\hline
\end{tabular}

Table 8. Robustness for MON and DES.

\begin{tabular}{cccccc}
\hline \multirow{2}{*}{ S. No. } & \multirow{2}{*}{ Parameter } & \multicolumn{2}{c}{ MON } & \multicolumn{2}{c}{ DES } \\
\cline { 3 - 6 } & & Peak area & Tailing factor & Peak area & Tailing factor \\
\hline 1 & Initial Sample & $2,812,194$ & 1.164 & $3,423,037$ & 1.060 \\
2 & Flow rate $(+0.2 \mathrm{ml} / \mathrm{min})$ & $3,192,458$ & 1.163 & $3,970,475$ & 1.056 \\
3 & Flow rate $(-0.2 \mathrm{ml} / \mathrm{min})$ & $2,412,494$ & 1.164 & $3,174,376$ & 1.047 \\
4 & Temp. change (10\% more) & $2,983,302$ & 1.163 & $3,879,560$ & 1.059 \\
5 & Temp. change (10\% less) & $2,355,063$ & 1.167 & $3,052,650$ & 1.055 \\
& \% RSD & & 0.14 & & 0.49 \\
\hline
\end{tabular}

Table 9. Ruggedness for MON and DES.

\begin{tabular}{cccr}
\hline & & & MON \\
S. No. & Parameter & Peak area & Peak area \\
\cline { 3 - 4 } 1 & Analyst-1 & $2,812,954$ & $3,420,257$ \\
2 & Analyst-2 & $2,813,565$ & $2,817,759$ \\
& \% RSD & 0.015 & 0.170 \\
\hline
\end{tabular}


Satisfactory recoveries ranging from $99.59 \%$ - 99.82\% for MON and $99.60 \%-99.80 \%$ for DES respectively were obtained by the proposed method. This indicates that the proposed method was accurate.

The linearity was found satisfactory for the drugs in the range $10-30 \mu \mathrm{g} / \mathrm{ml}$ for MON and $5-15 \mu \mathrm{g} / \mathrm{ml}$ for DES. The correlation coefficient was found to be 0.999 for both MON and DES. This indicates that the method was linear.

The limit of detection and limit of quantification for MON were found to be $0.176 \mu \mathrm{g} / \mathrm{ml}$ and $0.587 \mu \mathrm{g} / \mathrm{ml}$ and for DES were found to be $0.087 \mu \mathrm{g} / \mathrm{ml}$ and $0.292 \mu \mathrm{g} / \mathrm{ml}$ respectively, which indicate the sensitivity of the method.

The deliberate changes in the method and operational conditions have not much affected the chromatograms. This indicates that the proposed method was robust and rugged.

\section{Conclusion}

The proposed RP-HPLC method was simple, specific, sensitive, precise and accurate and can be used for simultaneous estimation of MON and DES in bulk samples and its tablet dosage forms.

\section{References}

[1] Government of India (2014) Indian Pharmacopoeia, Volume II. Ministry of Health and Family Welfare, The Indian Pharmacopoeia Commission, Ghaziabad, 2247 (Montelukast).

[2] Jarvis, B. and Markham, A. (2000) Montelukast. Drugs, 59, 891-928. http://dx.doi.org/10.2165/00003495-200059040-00015

[3] Neil, O.J.M. (2006) The Merck Index: An Encyclopedia of Chemicals Drug and Biologicals. 14th Edition, Merck Research Laboratories, Division of Merck and Co. Inc., White House Station, NJ, 1080 (Montelukast) \& 496 (Desloratadine).

[4] Murdoch, D., Goa, K.L. and Keam, S.J. (2003) Desloratadine. Drugs, 63, 2051-2077. http://dx.doi.org/10.2165/00003495-200363190-00010

[5] Sweetman, S.C. (2011) Martindale: The Complete Drug Reference, Volume A. 37th Edition, Pharmaceutical Press, London, 1240 (Montelukast) \& 626 (Desloratadine).

[6] CIMS (Current Index of Medical Specialities) (2015) UBM Medica India Pvt. Limited, Bangalore, Jan-April, 453 (Montelukast) \& 450 (Desloratadine).

[7] IDR Drug Triple $i$ Compendium (Indian Drug Review) (2015) UBM Medica India Pvt. Limited, Bangalore, 2, 53 (Montelukast) \& 217 (Desloratadine).

[8] Davis, B.E., Todd, D.C. and Cockcroft, D.W. (2005) Effect of Combined Montelukast and Desloratadine on the Early Asthmatic Response to Inhaled Allergen. Journal of Allergy and Clinical Immunology, 116, 768-772. http://dx.doi.org/10.1016/j.jaci.2005.06.014

[9] Patel, S.V., Patel, G.F. and Pipaliya, S.G. (2012) Derivative Spectroscopic Method for Simultaneous Estimation of Montelukast Sodium and Desloratadine in Bulk and Combined Dosage Form. Inventi Imapct: Pharmaceutical Analysis and Quality Assurance, 2, 82-85.

[10] Rima, M.B. and Dipti, B.P. (2013) Simultaneous Estimation of Montelukast Sodium and Desloratadine by Ratio Spectra Derivative Spectrophotometry Method in Combined Dosage Forms. Journal of Chemical and Pharmaceutical Research, 5, 193-199.

[11] Jain, R.R., Patil, P.O. and Bari, S.B. (2013) Simultaneous Estimation of Montelukast Sodium and Desloratadine in Bulk and in Tablet Formulation by UV Spectrophotometry. Indian Drugs, 50, 30-35.

[12] Rima, M.B. and Dipti, B.P. (2013) RP-HPLC Method for Simultaneous Estimation of Montelukast Sodium and Desloratadine in Combined Dosage Form. Article ID: PHARMATUTOR-ART-1735.

[13] Vibhuti, R.C. and Jitendra, P. (2012) Simultaneous Estimation of Montelukast Sodium and Desloratadine by RP-HPLC in their Marketed Formulation. International Journal of Chem Tech Research, 4, 1402-1407.

[14] Kalyankar, T.K., Kokate, R.H. and Kakade, R.B. (2012) RP-HPLC Method for Simultaenous Estimation of Montelukast Sodium and Desloratadine from Bulk and Tablets Formulation. International Research Journal of Pharmacy, 3, 343-347.

[15] Mallesham, B., Geetha, K., Uma Maheswar Rao, V. and Rama Rao, N. (2014) Simultaneous Estimation of Desloratadine and Montelukast in Bulk and Pharmaceutical Formulations by RP-HPLC. International Journal of Innovative Technology and Research, 2, 1181-1186.

[16] ICH Harmonised Tripartite Guideline (2011) Validation of Analytical Procedures: Text and Methodology, Q2(R1), Geneva, 1-13. 